\title{
Spatial Models of River Channel Planforms in Geographic Information System
}

\author{
Liang Leng ${ }^{*}$, Yan Zhang2 \\ ${ }^{1}$ Applied Technology College, Jilin University, Changchun, China \\ ${ }^{2}$ Zhejiang Institute of Geological Survey, Hangzhou, China \\ Email: "lengliang@jlu.edu.cn
}

Received 8 January 2016; accepted 26 February 2016; published 1 March 2016

\begin{abstract}
Rivers which are important objects in real world need be appropriately described in Geographic Information System to be conveniently inquired and detailed analyzed for human being. Many spatial models were proposed in the past, but spatial models with regard to river channel planforms (RCPs) are lesser-known. This work proposes spatial models of river channel planforms (SMRCPs) based on the properties of river channel planforms in the real world and the spatial relation theory. We proposed the segment conditions based on RCPs properties in Geographic Information System to describe rivers in the real world by SMRCPs in detail.
\end{abstract}

\section{Keywords}

\section{Spatial Models, River Channel Planforms, Segment Condition, Sinuous, Braided}

\section{Introduction}

Rivers are widely regarded as the world's most important objects which influence human settlement, development of agriculture and industry, transport, and disasters, the human activity moreover makes river changed in morphology, water quality, and biodiversity which could significantly react back to human activity [1]-[5]. River morphology has been a subject of great challenge of scientists and engineers who recognize that any effort with regard to river engineering must be based on a proper understanding of the morphological features involved and the responses to the imposed changes.

A river channel planform (RCP) is mostly like a narrow band, which is nearly linear for the width of the channel is much than its length, contained some bars. In Geographic Information System a RCP is almost described as a narrow region with some holes or merely a line when the width of the channel is too small to be described as a narrow region at a specific scale. Spatial relations are spatial constrains among spatial objects such as points, lines and regions, which can be utilized to speed up spatial query, analysis and graphic display. Users must employ the spatial relations between objects at different time to make the change detection of river channel planforms (RCPs) faster and more accurate. The spatial relations between RCPs could be mostly represented by region and region, line and region, line and line when the planform should be described as a line, moreover spa-

${ }^{*}$ Corresponding author. 
tial relations between region-holes and line-holes must be considered. However, regions or lines which represent RCPs are not only the simple regions or lines but also complicated ones, because river channels are in various forms.

A good understanding of RCPs is needed to analyze the spatial relations between different ones. In this paper, to better analyze the spatial relations between planforms of river channels, RCPs were represented by two straight lines with/without holes or a single straight line when the width is too small to describe in Geographic Information System.

\section{River Channel Planforms in the Real World}

RCPs in the real world are diversiform and complicated because of the impact of nature factors such as earthquake, flood and geological formation, and anthropogenic influence such as building dams, destroying plants on banks and repairing channels. Every river channel planform is different in detail thus there is no one spatial model fits all. Leopold and Wolman firstly proposed the conception of RCPs [6]. According to direct observation Drury provided the first complete classification of river channel planforms which is divided into eight types of river channel planform models such as meandering channel, braided channel, straight channel, deltaic distributary channel, anabranching channel, reticulate channel and Irregular channel [7]. The classification by Brice based on four major planform properties that are most readily observed on aerial photographs: sinuous canaliform, sinuous point bar, sinuous braided, and nonsinuous braided [8]. Miall divided RCP into braided, meandering, reticulate, and straight ones based on its properties [9]. The classification by Rust based on degrees of sinuous and braiding is the same as Miall's [10]. Qian et al. proposed the classification which is consist of wandering channel, meandering channel, straight channel, and anabranching channel, the first difference between the classification of Qian et al. and Rust is whether anabranching channel and reticulate channel is the same RCP type [11]. According to existing classifications the key characters of RCP classification are degrees of sinuous, braiding, and anabranching which are illustrated in Figures 1(a)-(c) respectively. In Figure 1(a) the RCP is differentiated by degrees of sinuous. In Figure 1(b) the RCP is differentiated by degrees of braiding. In Figure 1(a) the RCP is differentiated by degrees of anabranching.

Because the characters of braiding and anabranching are easily confused for people and difficult to differentiated in Geographic information system, we make the character of anabranching degress belong to the degrees of braiding and use the degrees of sinuous and braiding to classify RCPs. In this paper RCPs are classified into nonsinuous canaliform, sinuous canaliform, nonsinuous braided, and sinuous braided based on the characters of braiding and sinuous which are illustrated in Figure 2(a)-(d) respectively. Nonsinuous canaliform is illustrated in Figure 2(a). Sinuous canaliform is illustrated in Figure 2(b). Nonsinuous braided is illustrated in Figure 2(c). sinuous braided is illustrated in Figure 2(d).

\section{Spatial Models of RCPs in Geographic Information System}

Spatial models of RCPs (SMRCPs) in Geographic Information System root in RCPs of the real world, and they have some special properties. First of all, SMRCPs in GIS could be described by single irregular curve, double irregular curves, and double irregular curves with holes in the wake of different scales. In addition, double irregular curves with single hole and double irregular curves with multiple holes are different in spatial relations, we consider them as two cases. Finally the degree of sinuous is not the key property to distinguish objects in spatial relation, therefore we consider irregular curves as the same type in despite of different degree of sinuous. In this paper, SMRCPs are divided into single irregular curve, double irregular curves, double irregular curves with single hole, and double irregular curves with multiple holes which are illustrated in Figures 3(a)-(d) respectively. Figure 3(a) illustrates single irregular curve of SMRCP. Figure 3(b) illustrates double irregular curves of SMRCP. Figure 3(c) illustrates double irregular curves with single hole of SMRCP. Figure 3(d) illustrates double irregular curves with multiple holes of SMRCP. The irregular curves are consist of interior and boundary (two extreme points), and the holes are consist of interior (H-interior) and boundary (H-boundary).

However, irregular curves are so complicated and various that they are difficult to be depict in computer technology and to be understood by people, in order to better describe SMRCPs we simplify irregular curves to straight lines, and we called the new spatial models simple spatial models of river channel planforms (SSMRCPs). Also, SSMRCPs could easily express and analyze the spatial relations of RCPs. SSMRCPs a differentiated to single straight line (SSL), double straight lines (DSL), and double straight lines with single hole 


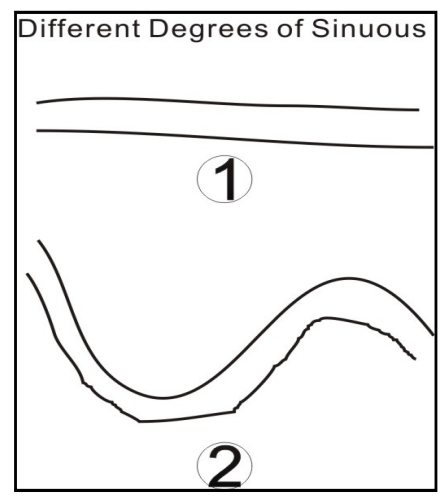

(a)

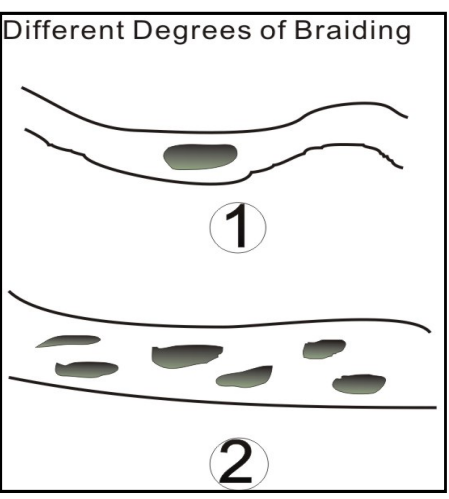

(b)

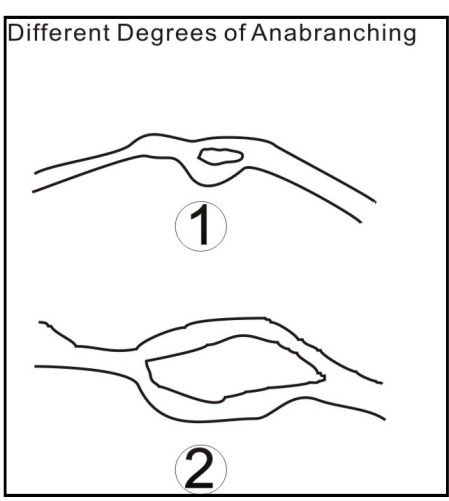

(c)

Figure 1. The three characters of RCP classification are illustrated through (a) to (c).

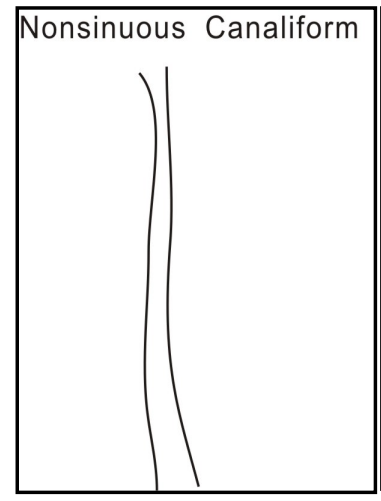

(a)

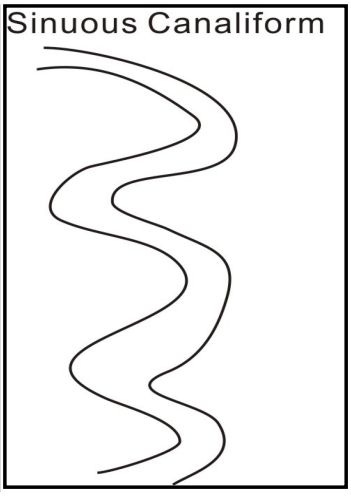

(b)

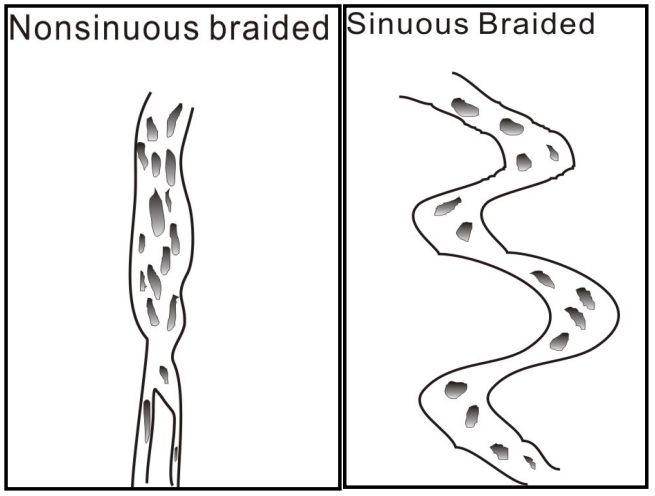

(c)

(d)

Figure 2. The four types of RCPs are illustrated through (a) to (d).

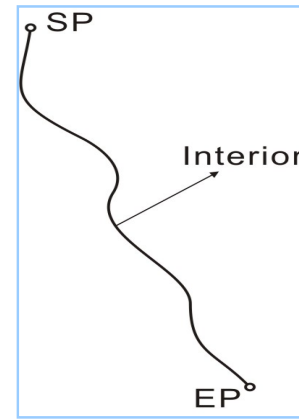

(a)

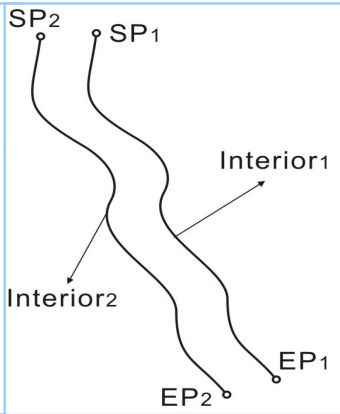

(b)

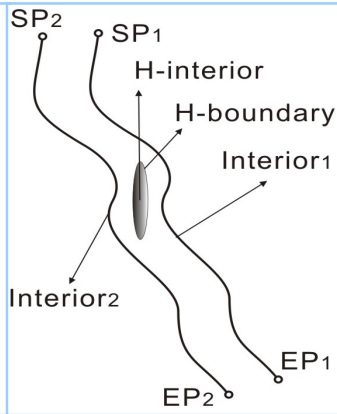

(c)

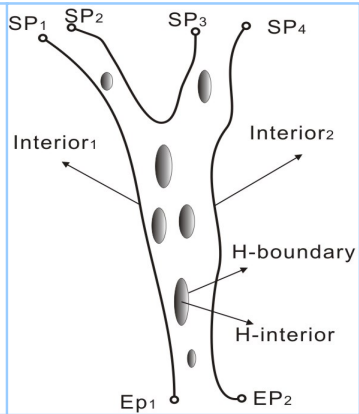

(d)

Figure 3.The four types of SMRCPs are illustrated through (a) to (d).

(DSLSH), and double straight lines with multiple holes (DSLMH) which are shown in Figures 4(a)-(d) respectively. Figure 4(a) shows SSL which is a straight line with interior and boundary (two extreme points), Figure 4(b) shows DSL which are consist of two single straight lines, Figure 4(c) shows DSLSH which are consist of two single straight lines and a hole within, Figure 4(d) shows DSLMH which are consist of two single straight lines and several holes within.

\section{River Descriptions by SMRCPs}

Rivers in real world are so complicated that they are difficult to be described by only one type of SMRCPs, that is to say, a segment of a river can be well described by one type of SMRCPs, and another segment of the 
river could be well described by else type of SMRCPs. In order to suitably describe a river we segment it to several segments by the segment conditions which could make river descriptions by SMRCPs clearly .In this paper we proposed two conditions to segment rivers as follows:

Condition 1. If Straight line A and $\alpha$ respectively extend a length of $\varepsilon_{1}, \varepsilon_{2}, \delta_{1}$, and $\delta_{2}$ which are arbitrarily small distances, the spatial model is the same, then the segment is suitable or else unsuitable. The situation is shown in Figure 5.

In Figure 5(a) after Straight line A and $\alpha$ respectively extend a length of $\varepsilon_{1}, \varepsilon_{2}, \delta_{1}$, and $\delta_{2}$ the spatial model will change, therefore, it is not suitable to segment the river at this position. In Figure 5(b) after Straight line A and $\alpha$ respectively extend a length of $\varepsilon_{1}, \varepsilon_{2}, \delta_{1}$, and $\delta_{2}$, the spatial model did not change, therefore, it is suitable to segment the river at this position.

Condition 2. If a river in real world becomes wider, meanwhile, the spatial models developed from SSL to DSL, we segment the river into two segments which are described by SSL and DSL as shown in Figure 6. Figure 6(a) shows a river becomes wider from SSL to DSL. Figure 6(b) shows the segment line which is segment the river to two segments. Figure 6(c) shows two river segments corresponding to two spatial models as SSL and DSL.

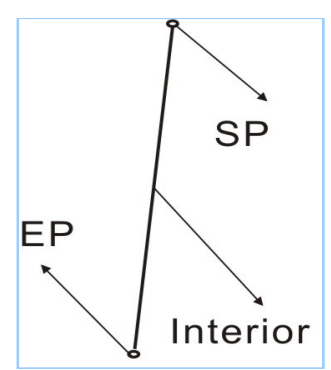

(a)

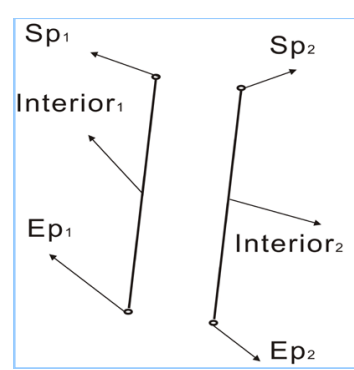

(b)

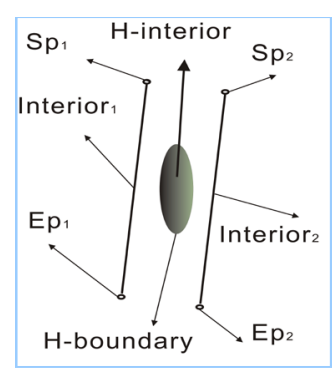

(c)

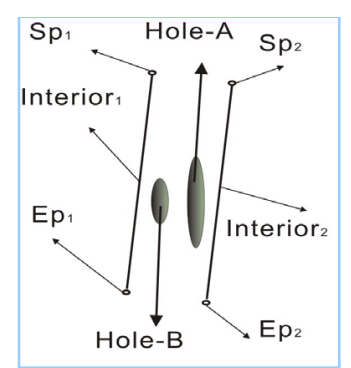

(d)

Figure 4. The four types of SMRCPs are illustrated through (a) to (d).

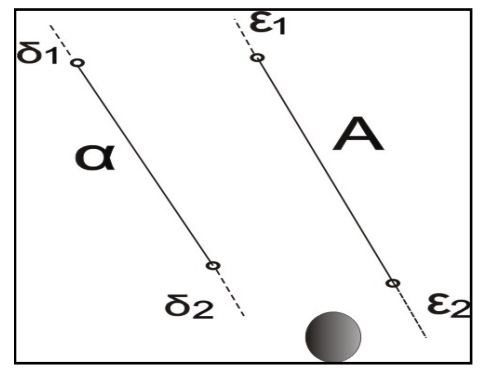

(a)

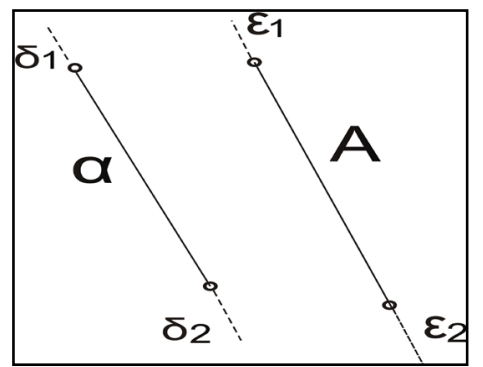

(b)

Figure 5. How can a river suitalbely to be segmented into two segments?

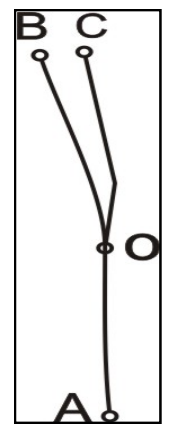

(a)

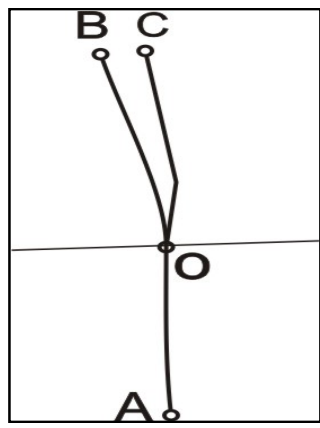

(b)

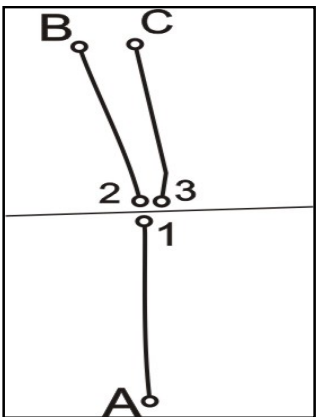

(c)

Figure 6. A river is segmented into two segments which are described by SSL and DSL. 


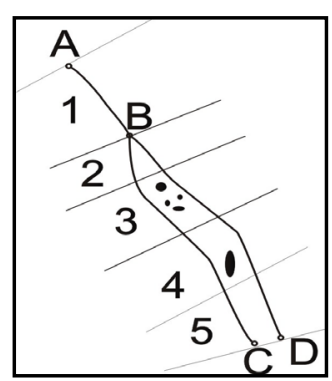

Figure 7. A river was segmented into 5 segments and respectively described by corresponding types of SSMRCPs.

Based on the conditions above we could segment a river into several segments and best described by corresponding SMRCPs in detail which are illustrated in Figure 7. Segment 1 is corresponding to SSL, Segment 2 is corresponding to DSL, Segment 3 is corresponding to DSLMH, Segment 4 is corresponding to DSLSH, Segment 5 is corresponding to DSL. However, the segments can be suitable to be described by SMRCPs but the river may be segmented by other ways.

\section{Conclusions}

This paper proposed SMRCPs to describe the RCPs which are important for human beings. For describing the river in detail we proposed the segment conditions to segment the rivers. However, we just construct such spatial models idea, the method to express SMRCPs in computers should be developed in the future work.

\section{Acknowledgements}

The authors would like to sincerely thank the anonymous reviewers whose efforts significantly improved the quality of the research presented.

\section{References}

[1] Perillo, G.M.E., Pérez, D.E., Piccolo, M.C., Palma, E.D. and Cuadrado, D.G. (2005) Geomorphologic and Physical Characteristics of a Human Impacted Estuary: Quequén Grande River Estuary, Argentina. Estuarine, Coastal and Shelf Science, 62, 301-312. http://dx.doi.org/10.1016/j.ecss.2004.09.018

[2] Gregory, K.J. (2006) The Human Role in Changing River Channels. Geomorphology, 79, 172-191. http://dx.doi.org/10.1016/j.geomorph.2006.06.018

[3] Billen, G., Garnier, J., Ficht, A. and Cun, C. (2001) Modeling the Response of Water Quality in the Seine River Estuary to Human Activity in its Watershed over the Last 50 Years. Estuarie, 24, 977-993. http://dx.doi.org/10.2307/1353011

[4] Zhang, J., Zhang, Z.F., Liu, S.M., Wu, Y., Xiong, H. and Chen, H.T. (1999) Human Impacts on the Large World Rivers: Would the Changjiang (Yangtze River) Be an Illustration? Global Biogeochemical Cycles, 13, 1099-1105. http://dx.doi.org/10.1029/1999GB900044

[5] Vanacker, V., Molina, A., Govers, G., Poesen, J., Dercon, G. and Deckers, S. (2005) RiverChannel Response to Shortterm Human-Induced Change in Landscape Connectivity in Andean Ecosystems. Geomorphology, 72, 340-353. http://dx.doi.org/10.1016/j.geomorph.2005.05.013

[6] Leopold, L.B. and Wolman, M.G. (1957) River Channel Patterns, Braided, Meandering and Straight. U.S. Geol. Surv. Paper. 282-B.

[7] Drury, G.H. (1969) Relation on Morphology to Runoff Frequency. In: Chorley, R.J., Ed., Water Soil and Man, Methuen, London, 418-430.

[8] Birce, J.C. (1969) Planform Properties of Meandering River, River Meandering, Proceedings of the October. 1983. Rivers “83 Conference”, ASCE, New Orleans. Louisiana, 1-15.

[9] Miall, A.D. (1997) A Review of the Braided River Depositional Environment. Earth Science Reviews, 13, 1-62. http://dx.doi.org/10.1016/0012-8252(77)90055-1

[10] Miall, A.D. (1996) The Geology of Fluvial Deposits (Sedimentrary Facies. Basin Analysis, and Petroleum Geology). 
Springer. 565.

[11] Rust, B.R. (1996) A Classification of Alluvial Channel Systems. In: Miall, A.D., Ed., Fluvial Sedimentology, Can. Soc. Petrol. Geol. Mem., 5, 187-198. 